Pesq. Vet. Bras. 36(Supl.1):106-112, junho 2016

DOI: $10.1590 /$ S0100-736X2016001300016

\title{
Effects of chronic mild stress on parameters of bone assessment in adult male and female rats ${ }^{1}$
}

\author{
Fabrício L. Valente ${ }^{2}$, Anna Paula B.R. Ferreira3 ${ }^{3}$, Leonardo D. da Costa ${ }^{4}$, Mário J.Q. \\ Louzada $^{5}$, Joaquin H. Patarroyo ${ }^{2}$ and Marlene I. Vargas ${ }^{2 *}$
}

\begin{abstract}
Valente F.L., Ferreira A.P.B.R., Costa L.D., Louzada M.J.Q., Patarroyo J.H. \& Vargas M.I. 2016. Effects of chronic mild stress on parameters of bone assessment in adult male and female rats. Pesquisa Veterinária Brasileira 36(Supl.1):106-112. Departamento de Veterinária, Universidade Federal de Viçosa, Campus Viçosa, Avenida Peter Henry Rolfs s/n, Viçosa, MG 36570-900, Brazil. E-mail: bebel@ufv.br

Osteoporosis is a multifactorial disease of high prevalence and has great impact on quality of life, because the effects on bone structure increase the risk of fractures, what may be very debilitating. Based on the observation that patients with depression have lower bone mineral density than healthy individuals, many studies have indicated that stress could be an aggravating factor for bone loss. This study evaluates the effect of a protocol of chronic mild stress (CMS) on parameters of bone assessment in male and female rats. Five 5-monh-old rats of each sex underwent a schedule of stressor application for 28 days. Stressors included cold, heat, restraint, cage tilt, isolation, overnight illumination, and water and food deprivation. Five rats of each sex were kept under minimum intervention as control group. The animals were weighed at beginning and end of the period, and after euthanasia had their bones harvested. Femur, tibia and lumbar vertebrae were analyzed by bone densitometry. Biomechanical tests were performed in femoral head and diaphysis. Trabecular bone volume was obtained from histomorphometric analysis of femoral head and vertebral body, as well as of femoral midshaft cross-sectional measures. Not all parameters analyzed showed effect of CMS. However, tibial and L4 vertebral bone mineral density and cross-sectional cortical/medullar ratio of femoral shaft were lower in female rats submitted to the CMS protocol. Among male rats, the differences were significant for femoral trabecular bone volume and maximum load obtained by biomechanical test. Thus, it could be confirmed that CMS can affect the balance of bone homeostasis in rats, what may contribute to the establishment of osteopenia or osteoporosis.
\end{abstract}

INDEX TERMS: Stress, osteoporosis, animal model, bone densitometry, bone histomorphometry, rat.

RESUMO.- [Efeito do estresse moderado crônico sobre parâmetros de avaliação óssea em ratos adultos machos e fêmeas.] A osteoporose é uma doença multifatorial,

\footnotetext{
${ }^{1}$ Received on February 16, 2016.

Accepted for publication on May 3, 2016.

${ }^{2}$ Departamento de Veterinária, Universidade Federal de Viçosa (UFV), Campus Viçosa, Avenida Peter Henry Rolfs s/n, Viçosa, MG 36570-900, Brazil. *Correspondig author: bebel@ufv.br

${ }^{3}$ Centro de Ciência Animal, Universidade Federal de Ouro Preto (UFOP), Morro do Cruzeiro, Ouro Preto, MG 35400-000, Brazil.

${ }^{4}$ Faculdade de Medicina Veterinária e Zootecnia, Universidade Estadual Paulista (Unesp), Campus Botucatu, Distrito de Rubião Júnior s/n, Botucatu, SP 18618-970, Brazil.

${ }^{5}$ Faculdade de Medicina Veterinária, Unesp, Campus Araçatuba, Rua Clóvis Pestana 793, Araçatuba, SP 16050-680, Brazil.
}

de alta prevalência e que tem um grande impacto na qualidade de vida, principalmente porque os efeitos sobre a estrutura do osso aumentam o risco de fraturas, que podem ser muito debilitantes. Com base na observação de que pacientes com depressão têm menor densidade mineral óssea que indivíduos saudáveis, muitos estudos têm indicado que o estresse pode ser um fator agravante para a perda óssea. Este estudo avalia o efeito de um protocolo de estresse moderado crônico (EMC) em parâmetros de avaliação óssea em ratos machos e fêmeas. Cinco animais de cada sexo, com cinco meses de idade, foram submetidos a um cronograma de aplicação de estressores durante 28 dias. Os estressores incluídos foram: frio, calor, contenção, inclinação da gaiola, isolamento, iluminação durante a noite e privação de água e ração. Cinco animais de cada sexo foram mantidos com um 
mínimo de intervenção como grupo controle. Os animais foram pesador no início e no final do período, e após eutanásia tiveram seus ossos coletados. Fêmur, tíbia e vértebra lombar foram analisados por densitometria óssea. Testes biomecânicos foram realizados na cabeça e na diáfise do fêmur. Volume trabecular ósseo foi obtido a partir de análise histomorfométricas da cabeça do fêmur e do corpo vertebral, bem como medidas da seção transversal diáfise femoral. Nem todos os parâmetros avaliados sofreram efeito do protocolo de EMC. No entanto, a densidade mineral óssea da tíbia e da vértebra $L 4$ e a razão osso cortical/medula da seção transversal da diáfise femoral foram menores nas fêmeas submetidas ao protocolo. Entre os ratos machos, as diferenças foram significativas no volume trabecular ósseo da cabeça femoral e na carga máxima obtida no teste biomecânico. Assim, confirma-se que o protocolo de EMC pode afetar o equilíbrio da homeostase óssea em ratos, o que pode contribuir para o estabelecimento de osteopenia ou osteoporose.

TERMOS DE INDEXAÇÃO: Estresse, osteoporose, modelo animal, densitometria óssea, histomorfometria óssea, rato.

\section{INTRODUCTION}

Osteoporosis is a high prevalence disease that affects predominantly women but also has great importance among men, and develops as the result of an imbalance between bone formation and resorption (WHO 2003), that are regulated by a variety of endocrine and immune mediators (Shea \& Miller 2005). Among the population aged 50 or more, one-third of women and one-fifth of men may be at high risk of fracture (Dawson-Hughes et al. 2012). It is estimated that the number of high-risk individuals for osteoporotic fractures will double from 2010 to 2040 worldwide (Odén et al. 2015). The disease is multifactorial and chronic exposure to glucocorticoid is considered an important cause of bone loss (Sambrook \& Lane 2001). Endogenous glucocorticoid plays a central role in the response to stress (de Kloet et al. 1998, Pacak \& McCarty 2000). Endogenous glucocorticoid levels increase with age and may have negative effects on bone metabolism (Weinstein et al. 2010). In humans, depression has been related to reduced bone mineral density (BMD), increasing the risk of osteoporosis (Cizza et al. 2009). In the study of stress, the chronic mild stress (CMS) model in rats and mice is widely used with the aim of inducing changes consistent with depression (Gamaro et al. 2003, Detanico et al. 2009, Lucca et al. 2009). However, these studies emphasize the neurological symptoms related to depression. In the CMS model, not only the glucocorticoid produced in response to stress can have an effect on bone metabolism but also norepinephrine also seems to play an important role (Yirmiya et al. 2006), what reiterates the complexity of factors involved. The connection between stress and bone metabolism is still poorly investigated. To contribute with additional information about this relationship, the present study evaluates bone parameters by histomorphometric, biomechanical and densitometric analyses in adult rats of both sexes submitted to a CMS protocol.

\section{MATERIALS AND METHODS}

Ethics statement. The ethics committee for animal use of the institution approved the procedures in this experiment (Protocol \#52/2009), based on current legislation.

Animals. Twenty 3-month-old Wistar rats (Rattus norvegicus) of both sexes were purchased from the Central Animal Facility of UFV. The animals were kept in plastic cages (five per cage) in an experimental room used exclusively for this study with cycles of $12 \mathrm{~h}$ light/dark, $20-24^{\circ} \mathrm{C}$. When they were 5 -months-old, CMS protocol was initiated for five males and five females. The remaining animals comprised the control group that did not undergo any procedure during the experiment.

Chronic mild stress. The design of CMS protocol used in this study was based on many sources found in the scientific literature (Gamaro et al. 2003, Dalla et al. 2005, Baker et al. 2006, Detanico et al. 2009, Lucca et al. 2009) and adapted to the facilities available. Eight stressors were applied, during 28 days (Table 1): (a) 2 hours of lower temperature, when the animals were kept in a plastic cage without wood shavings placed over bags of ice (temperature next to the floor of the cage was maintained around $10^{\circ} \mathrm{C}$ ); (b) 2 hours of heat, which was produced by an electric heater $(1500 \mathrm{~W})$ orientated to the open side of a cardboard box containing the cages, for partial thermal insulation so that temperature were maintained between 38 and $40^{\circ} \mathrm{C}$; (c) 12 hours of isolation, when the animals of each group were transferred to individual cages; (d) 3 hours of $45^{\circ}$ cage tilt; (e) 12 hours of water deprivation; (f) 12 hours of food deprivation; (g) 20 minutes of restraint, which was achieved by wrapping the animal in a cloth with hook-and-loop fasteners; and (h) overnight illumination, that was applied by transferring the cages to an adjacent room before the lights of the main room were turned off. On the 29th day from the begging of the experiment, the animals were euthanized and had femurs, tibias and lumbar vertebrae harvested and dissected. Body weights were recorded at the beginning and at the end of the experimental period.

Assessment of bone parameters. Right femur and tibia, and L4 vertebral body were fixed in formalin $10 \%$ and then analyzed in a densitometer DPX-A to obtain bone mineral content (BMC, grams) and bone mineral density (BMD, $\mathrm{g} / \mathrm{cm}^{2}$ ). Next, those same samples were submitted to histological process to obtain $5 \mu \mathrm{m}$ thick sections of decalcified bone stained by hematoxylin and eosin for histomorphometric analysis. The nomenclature used in this work follows that standardized by Parfitt et al. (1987). Vertebral bodies were sectioned along the sagittal axis and images of each slice were captured at a 100x magnification immediately caudal from the cranial growth plate and cranial from the caudal growth plate. Proximal epiphysis of the femurs were sectioned longitudinally and photographed immediately distal to the growth plate of the femoral head. Trabecular bone volume were obtained from micrographs by counting-points method and expressed as bone volume divided by total volume (BV/TV, \%). Femurs were also cross-sectioned at the middle portion of the diaphysis for: bone

Table 1. Schedule of stressors application during 28 days

\begin{tabular}{cccc}
\hline Day & Stressor & Start time & Duration \\
\hline $1,8,15$ and 22 & Cold & $14: 00$ & 2 hours \\
$2,9,16$ and 23 & Heat & $16: 00$ & 2 hours \\
$3,10,17$ and 24 & Isolation & $07: 00$ & 12 hours \\
$4,11,18$ and 25 & Cage tilt & $13: 00$ & 3 hours \\
$5,12,19$ and 26 & Water deprivation & $07: 00$ & 12 hours \\
& Food deprivation & $19: 00$ & 12 hours \\
$6,13,20$ and 27 & Standard conditions & \\
$7,14,21$ and 28 & Restraint & $07: 00$ & 20 minutes \\
& Overnight illumination & $19: 00$ &
\end{tabular}

Pesq. Vet. Bras. 36(Supl.1):106-112, junho 2016 
and medullary cavity diameters (B.Dm and Ma.Dm, $\mu \mathrm{m}$ ); cortical thickness (Ct.Wi, $\mu \mathrm{m}$ ); bone and medullary cavity area (B.Ar and Ma.Ar, $\mu \mathrm{m}^{2}$ ). Moreover, the relationship between cortical bone and medullary cavity was calculated (Ct.Wi/Ma.Dm and Ct.Ar/Ma.Ar). Mechanical properties of the left femurs were evaluated by flexo-compression to fracture of femoral head and three-point bending test to fracture of femoral diaphysis. The tests were conducted in a Universal Testing Machine (EMIC, DL3000 model), using a load cell at $2000 \mathrm{~N}$ at a speed of $5 \mathrm{~mm} /$ minute), as described by Carvalho et al. (2007). Maximum load to fracture (N) and stiffness (N/ $\mathrm{mm}$ ) were obtained in each test.

Data analysis. Effects of sex and stress on bone parameters as well as interactions were determined by 2 -way ANOVA. In case of significance, Holm-Sidak test was used as post-hoc test. Initial and final weights were compared by 2 -way repeated measures ANOVA, considering group (treatment $\mathrm{x}$ sex) and time (initial and final) as factors. Relationship between different parameters were evaluated by Pearson correlation test. A level of significance of 5\% was considered for all tests.

\section{RESULTS}

\section{Body weight}

After 28 days, correlation between initial and final body weights was 0.934 . Nevertheless, male rats subjected to CMS protocol showed a decrease in body weight compared to the beginning of the experiment (Fig.1).

\section{Bone densitometry}

Femoral BMC showed effect of sex ( $\mathrm{p}<0.001)$, but not of CMS or interaction between sex and CMS. Holm-Sidak test pointed the difference between the sexes (Fig.2A), with the highest values among males. For tibia BMC, an interaction effect between sex and CMS was observed $(p=0.006)$. The post-hoc analysis showed that the bone mineral content was higher in males subjected to CMS, while this effect was

\section{Body weight (g)}

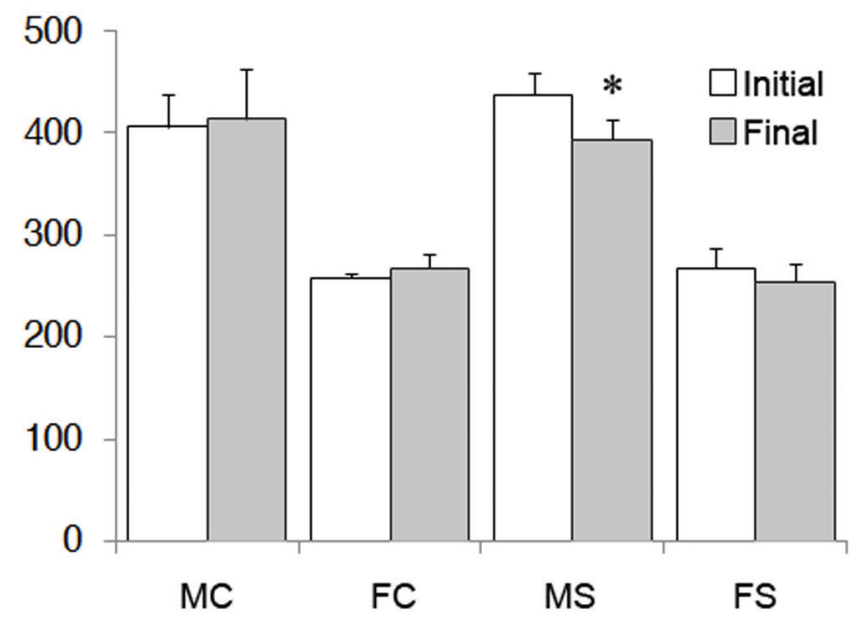

Fig.1. Graphical representation of initial and final body weight means and standard deviations, in grams. MC: male control; FC: female control; MS: male stress; FS: female stress. Significant differences in 2-way repeated measures ANOVA between initial and final body weight: ${ }^{*} \mathrm{p}<0.001$. There were no significant difference in initial body weight between treatments for each sex.
Bone Mineral Content ( $g$ )

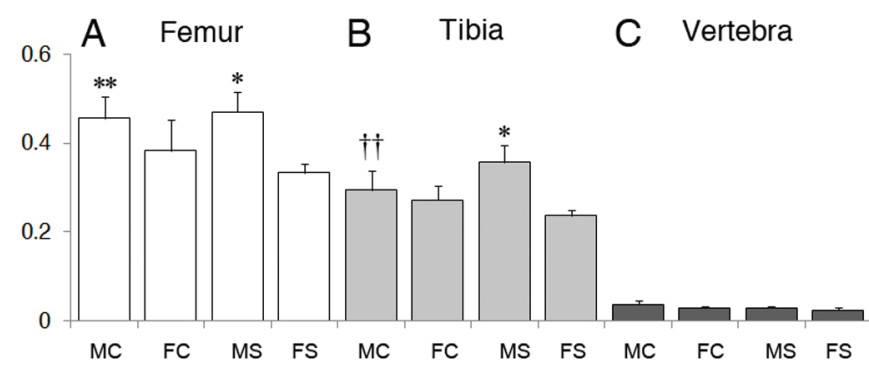

Bone Mineral Density $\left(\mathrm{g} / \mathrm{cm}^{2}\right)$

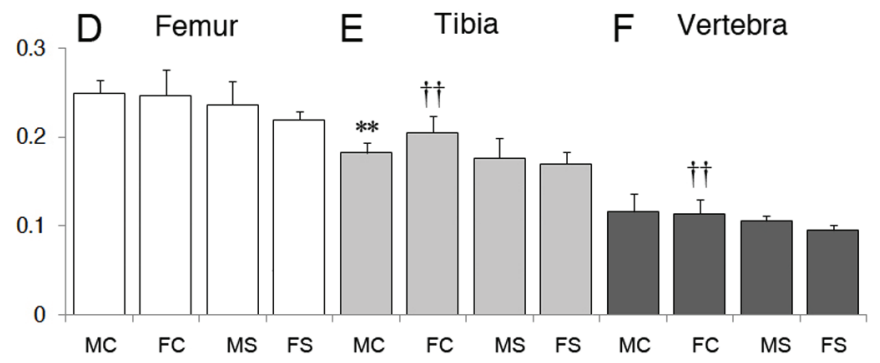

Fig.2. Graphical representation of bone mineral content (BMC) and bone mineral density (BMD) means and standard deviations, according to sex and treatment. Femoral (A), tibia (B) and vertebral (C) BMC. Femoral (D), tibia (E) and vertebral (F) BMD. MC: male control; FC: female control; MS: male stress; FS: female stress. Significant differences in Holm Sidak-test for sex within each treatment: ${ }^{*} \mathrm{p}<0.001$ and ${ }^{* *} \mathrm{p}<0.05$; and for treatment within each sex: $\uparrow \mathrm{p}<0.001$ and $\dagger \dagger \mathrm{p}<0.05$.

not seen in females (Fig.2B). Vertebral bodies did not show any significant differences between groups regarding to mineral content (Fig.2C).

Tibia and vertebral BMDs were affected by CMS $(p=0.016$ and $p=0.032$, respectively), with lower values in those groups subjected to the protocol. The p-value for the effect of CMS on femoral BMD was 0.050, and therefore post-hoc test was not performed, since a significance level of 5\% was chosen (Fig.2D). The Holm-Sidak test showed the difference between the sexes within the control groups, as well as the effect of stress on the tibia BMD tibia in females (Fig.2E). The post-hoc test, in the case of the vertebral body, identified only the effect of CMS in females (Fig.2F). BMD of any of the three bones showed no correlation with body weight $(\mathrm{p}<0.005)$.

\section{Bone histomorphometry}

B.Ar, Ma.Ar e Ct.Ar obtained from cross-section femoral analysis showed only effect of sex ( $p<0.001$ for the three measures). The post-hoc test revealed similar results between measurements, with higher values among males compared to females (Fig.3A-C).

Analysis of variance showed effects of sex on total diameter and medullary cavity diameter $(\mathrm{p}<0.001$ for both measures). Diameters are bigger among male than female rats, as revealed by post-hoc test (Fig.3D,E). However, cortical thickness was not only affected by sex $(\mathrm{p}=0.033)$ but also by CMS $(p=0.049)$. Although Holm-Sidak test was not 
able to demonstrate any difference, analysis of the graph indicates that CMS is able to reduce slightly the measurements of the cortical bone thickness (Fig.3F).

CMS was able to change the cortical bone thickness/ medullary cavity diameter ratio $(p=0.023)$. It decreased in animals subjected to the protocol, especially in females (Fig.4A). The same happened in the cortical/medullary area ratio, which decreased with CMS $(p=0.036)$. The post-hoc test also showed only difference between females (Fig.4B).

Correlation between body weight and the cross-sectional histomorphometric parameters is high (ranging from 0.773 to 0.939 ), except bone cortical/medullary cavity ratios (no correlation) and Ct.Wi (correlation coefficient = $0.594)$.

In femoral head, CMS and sex showed effect on trabecular bone volume, given by BV/TV, with p-values equal to 0.018 and 0.005 , respectively. The post-hoc test showed differences between male and female rats from control groups and between CMS and control rats from male groups (Fig.4C). In the vertebral body, sex and stress did not affect trabecular bone volume (Fig.4D). Femoral BV/TV correlates to body weight with coefficient of 0.566 .

\section{Mechanical testing}

The effect of sex was detected in maximum load registered for both head and shaft tests $(\mathrm{p}=0.002$ and $\mathrm{p}=0.007)$. CMS affected maximum load only in the former $(\mathrm{p}=0.035)$ in which control group showed highest means. Holm-Sidak
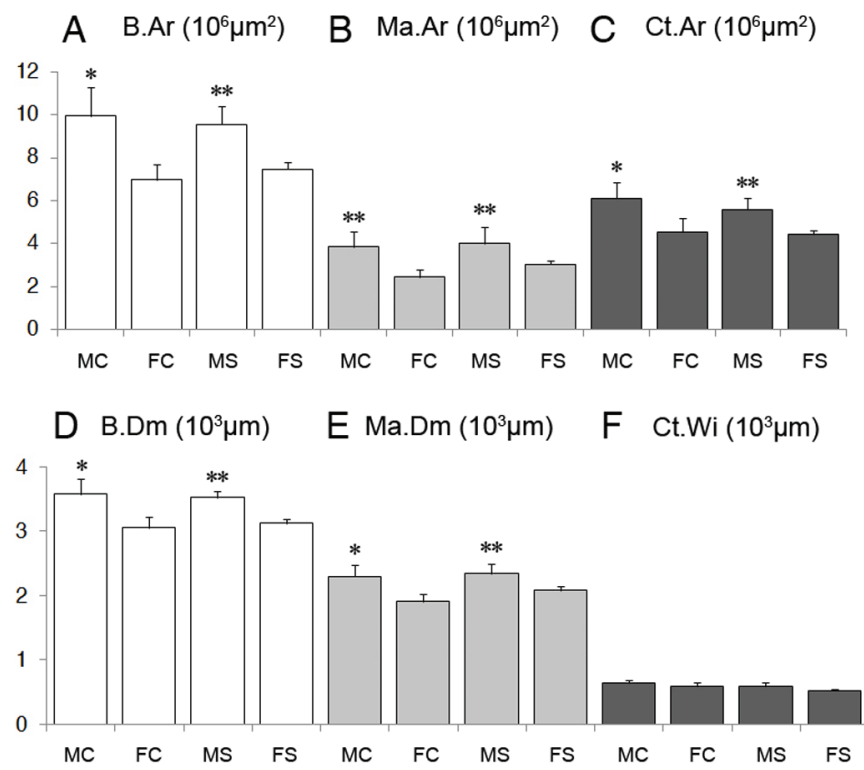

Fig.3. Graphical representation of means and standard deviations of femoral midshaft cross-section total area (B.Ar) (A), medullary area (Ma.Ar) (B) cortical area (Ct.Ar) (C), femoral midshaft cross-section total diameter (B.Dm) (D), medullary diameter (Ma.Dm) (E) and cortical width (Ct.Wi) (F), according to sex and treatment. MC: male control; FC: female control; MS: male stress; FS: female stress. Significant differences in Holm Sidak-test for sex within each treatment: ${ }^{*} \mathrm{p}<0.001$ and $* * \mathrm{p}<0.05$; and for treatment within each sex: $\uparrow \mathrm{p}<0.001$ and $+\dagger \mathrm{p}<0.05$.
A Ct.Wi/Ma.Dm

B Ct.Ar/Ma.Ar
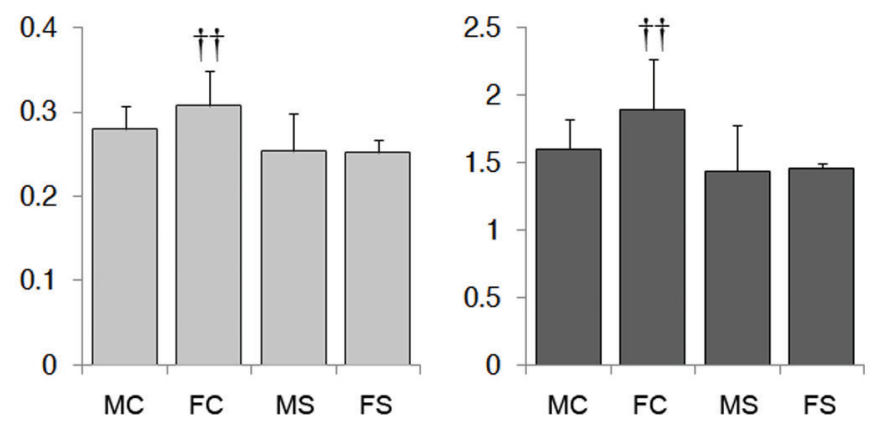

BV/TV $(\%)$

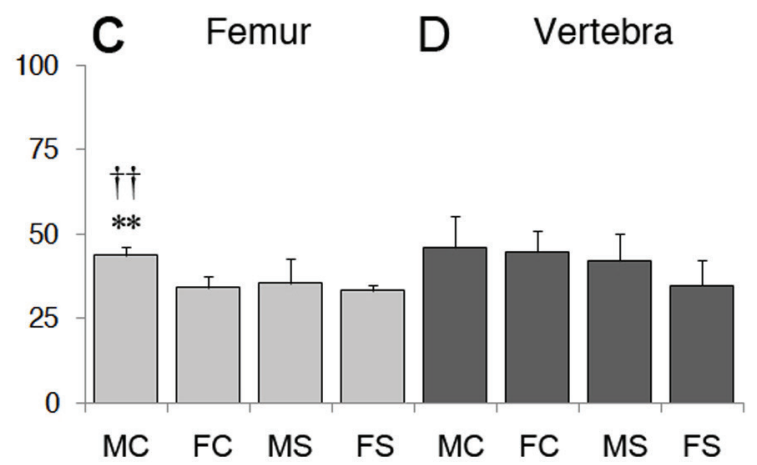

Fig.4. Graphic representation of means and standard deviations of the relationship between cortical bone thickness and marrow diameter (A) and bone and marrow area (B) in femoral midshaft cross-section, and trabecular bone volume (BV/TV) for femoral head (C) and vertebral body (D) according to sex and treatment. MC: male control; FC: female control; MS: male stress; FS: female stress. Significant differences in Holm Sidak-test for sex within each treatment: ${ }^{*} \mathrm{p}<0.001$ and ${ }^{* *} \mathrm{p}<0.05$; and for treatment within each sex: $\dagger \mathrm{p}<0.001$ and $\dagger \dagger \mathrm{p}<0.05$.

test then indicated the differences between sexes among the control groups and between treatments among males (Fig.5A). For the shaft, only the difference between males and females subjected to stress could be noted in the post-hoc test (Fig.5B). CMS-sex interaction showed influence on femoral head stiffness $(\mathrm{p}=0.021)$ but only difference between males and females in the groups subjected to CMS protocol was indicated by the Holm-Sidak (Fig.5C). The chart analysis reveals an inverse behavior of means. Males subjected to CMS showed higher stiffness than their control group, while the opposite occurs in females. Stiffness of the femoral shaft showed only the sex effect ( $\mathrm{p}=0.028)$. The post-hoc test did not identify any difference between the groups (Fig.5D).

Femur BV/TV showed a correlation coefficient of 0.537 with maximum load and 0.492 with the stiffness of the femoral head in biomechanical testing.

\section{DISCUSSION}

Chronic mild stress applied accordingly to the protocol of this study was able to cause weight loss in male rats. Rats increase their body weight until about 18 months of age 


\section{Maximum Load (N)}
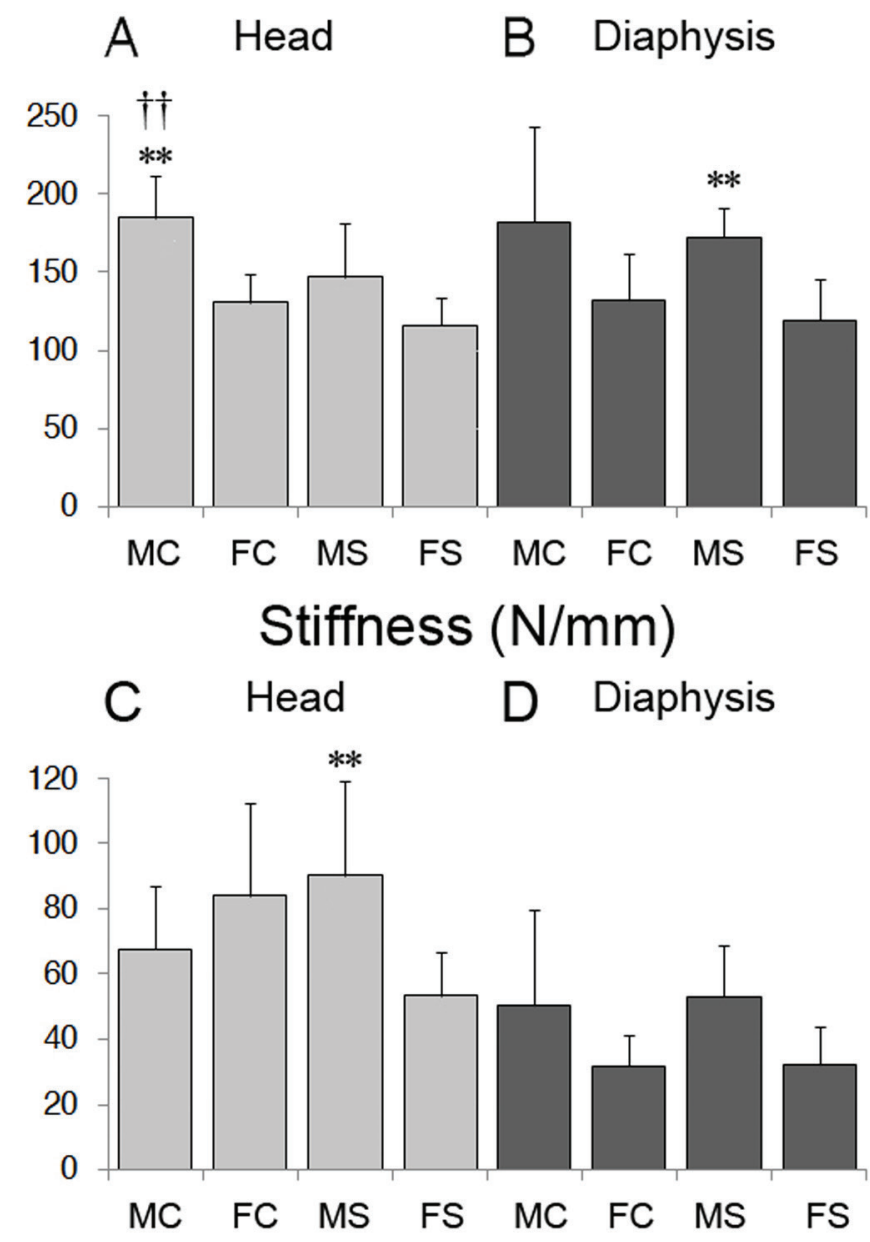

Fig.5. Graphical representation of means and standard deviations of femoral head (A) and diaphysis (B) maximum load, and femoral head (C) and diaphysis (D) stiffness, according to sex and treatment. MC: male control; FC: female control; MS: male stress; FS: female stress. Significant differences in Holm Sidak-test for sex within each treatment: ${ }^{*} \mathrm{p}<0.001$ and ${ }^{* *} \mathrm{p}<0.05$; and for treatment within each sex: $\uparrow \mathrm{p}<0.001$ and $\dagger \dagger \mathrm{p}<0.05$.

(Sengupta et al. 2005). Therefore, many authors refer to this effect as a reduction of body weight gain, because they use young animals (Marin et al. 2007, Garcia et al. 2009, Gong et al. 2011). However, not all researchers observe weight loss or reduction of body weight gain in rats submitted to CMS (Bekris et al. 2005). The results showed sexual dimorphism in the response of body weight changes to CMS, similar to results reported by García-Cáceres et al. (2010), who observed that rat body weight gain, when subjected to stress, was dimorphic, but apparently not related to sex hormones. Harris et al. (2006) used only immobilization as a chronic stressor in rats and observed that the initial weight loss is related to decreased food intake and increased energy expenditure, although anorexia can also be a symptom of depression. The protocol outlined for the present study used collective cages and the animals were subjected to frequent handling and change of cages for the application of stressors. For isolation, for example, the ration was placed in a pot on the floor of the cage, while in collective cages the ration was placed on the grid of the lid. Therefore, it was not possible to measure accurately the amount of food ingested by the animals throughout the experiment. Moreover, the effects of stress on feeding and body weight may depend on the circadian rhythm (Harris et al. 2002).

Bone densitometry is the standard tool for the diagnosis of osteoporosis based on parameters defined by the World Health Organization (WHO 1994). However, the result may vary depending on the method employed (Faulkner et al. 1999, Blake et al. 2002), the part of the skeleton that is analyzed (El Maghraoui et al. 2007, Mounach et al. 2009 ) and the body composition of the patient (Saarelainen et al. 2007). This occurs partly because, although osteoporosis is a systemic disease, bone loss is not uniform within the skeleton (Shea \& Miller 2005), as the activity of bone cells depends on the local blood supply and mechanical stimulation (Weinstein \& Manolagas 2000, Hazenberg et al. 2006). In medical practice, fracture risk assessment becomes much more reliable when combined with clinical risk factors (Syed \& Khan 2002, Leslie et al. 2002). Iwaniec \& Turner (2008) recommend that BMC would be used for interpreting densitometry data in animal models, because DMO dilutes the size of the bone, which is a crucial factor that determines bone strength. In the present work, BMC was greater in males subjected to CMS protocol than the control group. This difference was proportional to that obtained for bone area, which is assessed for BMD calculation, indicating that the animals selected to compose the group submitted to CMS protocol were bigger than the control group. This could not be detected at the beginning of the study, when the animals were selected accordingly to body weight, which was homogeneous at that time, as confirmed by repeated measures ANOVA (Fig.1). Thus, BMD gains importance in this work, being evaluated together with the other parameters, which is also recommended by those authors. Ovariectomized rat model is widely used to study osteoporosis, and Francisco et al. (2011) demonstrated that the age of the animals at the time of surgery, time of analysis after surgery and the specific site analyzed have influence on results, and changes of BMC are more intense in the distal femur while changes of BMD are more intense in the proximal portion of tibia.

In this study, some of the parameters evaluated changed due to CMS, mainly between females. According to Willner (1997), CMS model is difficult to establish, in addition to being laborious and requiring a lot of space and time. However, once established, it provides valuable information about problems that are extremely difficult to study by other means. It is important to consider that the type of response to a stressor depends crucially on the phenotypic plasticity, determined by interaction between environment and genome (Anisman \& Matheson 2005, Levine 2005). Immunological pathways also have great effect on the nervous system and the skeletal system, but there is scant knowledge about the interaction between them. Although norepinephrine is considered the major mediator of bone loss induced by stress (Yirmiya et al. 2006), the role of glucocorticoids is still likely, because they have direct and indirect 
action on bones, that results in bone loss (Ziegler \& Kasperk 1998, Manelli \& Giustina 2000, Lafage-Proust et al. 2003). The cardinal feature of glucocorticoid-induced osteoporosis is bone formation reduction (Mcllwain 2003, Tamura et al 2004), because it affects osteoblast proliferative and metabolic competence (Patschand et al. 2001) and induces osteoblast apoptosis (Lafage-Proust et al. 2003). Glucocorticoids also decrease intestinal calcium absorption and renal calcium reabsorption (Ziegler \& Kasperk 1998, Manelli \& Giustina 2000). Stress can also affect sex hormones production (Epel 2009). These hormones play an important role in bone maintenance (Riggs et al. 2002). However, the effect of stress on these hormones in animal models is contradictory (Tsuchiya \& Horii 1995, Retana-Márquez 2003, Chichinadze \& Chichinadze 2008). The main effect caused by CMS in females is estrous cycles irregularity (Dalla et al. 2005). Variation among data found in literature may occur not only by the variety of protocols used but also by the sexual dimorphism related to each type of stressor. Men have marked response when the stressor involves achievement or conquest, while women are more susceptible to stressors that involve social rejection (Stroud et al. 2002). Weinstein et al. (2010) showed that, as well as in humans, circulating glucocorticoid in mice increases with age and this increment is able to impair bone microarchitecture and strength. Osteoporotic fractures do not occur naturally in rats and bone fragility needs to be assessed by biomechanical tests (Turner et al. 2001). Many factors influence these tests such as bone type, temperature, degree of hydration and autolysis; therefore, data should always be relative (Turner \& Burr 1993). In the present study, maximum load achieved in flexo-compression test of the femoral head of male rats was the only parameter that showed influence by CMS in statistical analysis. The mild bone loss or sometimes non-significant differences between CMS and control groups may be due not only to the induction mechanism but also to the time of observation. El Khassawna et al. (2013), for example, have shown that tibia BV/TV of ovariectomized rats fed with multideficient diet, assessed by microcomputed tomography, can achieve less than $10 \%$ after three months of induction. Feik et al. (1997) showed that in humans, cortical area of cross-sections from femoral midshaft increases in both sexes until the $7^{\text {th }}$ decade and then it starts to decline, more pronounced in women. In addition, medullary area expanded over time, about two times in men and three times in women. In the ovariectomized rat model of osteoporosis, there is periosteal bone growth and enlargement of medullary cavity due to increment on endosteal bone resorption (Jee \& Yao 2001). In the present work, changes on cross-sectional measures of femoral shaft caused by CMS could be evident only when the ratio of cortical to medullary cavity.

\section{CONCLUSIONS}

The protocol of chronic mild stress used in this study showed negative effects on some of the bone densitometric, histomorphometric and biomechanical parameters analyzed, especially in females.

Given the impact that stress takes place in modern life and hence depression, the results obtained in the present study indicate that chronic mild stress is useful as a complimentary model for the study of osteoporosis.

Acknowledgements.- The authors thank CAPES, CNPq e FAPEMIG for financial support.

Conflict of interest statement.- The authors have no competing interests.

\section{REFERENCES}

Anisman H. \& Matheson K. 2005. Stress, depression, and anhedonia: caveats concerning animal models. Neurosci. Biobehav. Rev. 29:525-546.

Baker S.L., Kentner A.C., Konkle A.T.M., Barbagallo L.S.M. \& Bielajew C. 2006. Behavioral and physiological effects of chronic mild stress in female rats. Physiol. Behav. 87:314-322.

Bekris S., Antoniou K., Daskas S. \& Papadopoulou-Daifoti Z. 2005. Behavioural and neurochemical effects induced by chronic mild stress applied to two different rat strains. Behav. Brain Res. 161:45-59.

Blake G.M., Knapp K.M. \& Fogelman I. 2002. Absolute fracture risk varies with bone densitometry technique used. J. Clin. Densitom. 5:109-116.

Carvalho A.A.F., Louzada M.J.Q. \& Riso N.D.M. 2007. Hindlimb unloading producing effects on bone biomechanical properties in mature male rats. Braz. J. Morphol. Sci. 24:175-179.

Chichinadze K. \& Chichinadze N. 2008. Stress-induced increase of testosterone: Contributions of social status and sympathetic reactivity. Physiol. Behav. 94:595-603.

Cizza G., Ravn P., Chrousos G.P. \& Gold P.W. 2001. Depression: A major, unrecognized risk factor for osteoporosis? Trends Endocrinol. Metabol. 12:198-203.

Dalla C., Antoniou K., Drossopoulou G., Sagoraris M., Kokras N., Sfikakis A. \& Papadopoulou-Daifoti Z. 2005. Chronic mild stress impact: Are females more vulnerable? Neuroscience 135:703-714.

Dawson-Hughes B., Looker A.C., Tosteson A.N.A., Johansson H., Kanis J.A. \& Melton III L.J. 2012. The potential impact of the National Osteoporosis Foundation guidance on treatment eligibility in the USA: an update in NHANES 2005-2008. Osteoporos. Int. 23:811-820.

De Kloet E.R., Vreugdenhil E., Oitzl M.S. \& Joël M. 1998. Brain corticosteroid receptor balance in health and disease. Endocr. Rev. 19:269-301.

Detanico B.C., Piato A.L., Freitas J.J., Lhullier F.L., Hidalgo M.P., Caumo W. \& Elisabetsky E. 2009. Antidepressant-like effects of melatonin in the mouse chronic mild stress model. Eur. J. Pharmacol. 607:121-125.

El Khassawna T., Böcker W., Govindarajan P., Schliefke N., Hürter B., Kampschulte M., Schlewitz G., Alt V., Lips K.S., Faulenbach M., Möllmann H., Zahner D., Dürselen L., Ignatius A., Bauer N., Wenisch S., Langheinrich A.C., Schnettler R. \& Heiss C. 2013. Effects of multi-deficiencies-diet on bone parameters of peripheral bone in ovariectomized mature rat. PLoS One 16: e71665.

El Maghraoui A., Mouinga Abayi D.A., Rkain H. \& Mounach A. 2007. Discordance in diagnosis of osteoporosis using spine and hip bone densitometry. J. Clin. Densitom. 10:153-156.

Epel E.S. 2009. Psychological and metabolic stress: a recipe for accelerated cellular aging? Hormones 8:7-22.

Faulkner K.G., Von Stetten E. \& Miller P. 1999. Discordance in patient classification using T-scores. J. Clin. Densitom. 2:343-350.

Feik S.A., Thomas C.D. \& Clement J.G. 1997. Age-related changes in cortical porosity of the midshaft of the human femur. J. Anat. 191:407-416.

Francisco J.I., Yu Y., Oliver R.A. \& Walsh W.R. 2010. Relationship between age, skeletal site, and time post-ovariectomy on bone mineral and trabecular microarchitecture in rats. J. Orthop. Res. 29:189-196.

Gamaro G.D., Manoli L.P., Torres I.L.S., Silveira R. \& Dalmaz C. 2003. Effects of chronic variate stress on feeding behavior and on monoamine levels in different rat brain structures. Neurochem. Int. 42:107-114.

Garcia L.S.B., Comim C.M., Valvassori S.S., Réus G.Z., Stertz L., Kapczinski F., Gavioli E.C. \& Quevedo J. 2009. Ketamine treatment reverses behavior- 
al and physiological alterations induced by chronic mild stress in rats. Prog. Neuropsychopharmacol. Biol. Psychiatry 33:450-455.

García-Cáceres C., Diz-Chaves Y., Lagunas N., Calmarza-Font I.S., Azoitia I., Garcia-Segura L.M., Frago L.M., Argente J. \& Chowen J.A. 2010. The weight gain response to stress during adulthood is conditioned by both sex and prenatal stress exposure. Psychoneuroendocrinology 35:403-413.

Gong Y., Chai Y., Ding J.H., Sun X.L. \& Hu G. 2011. Chronic mild stress damages mitochondrial ultrastructure and funtion in mouse brain. Neurosci. Lett. 488:76-80.

Harris R.B.S., Palmondon J., Leshin S., Flatt W.P. \& Richard D. 2006. Chronic disruption of body weight but not of stress peptides or receptors in rats exposed to repeated restraint stress. Horm. Behav. 49:615-625.

Harris R.B.S., Zhou J., Mitchell T., Hebert S. \& Ryan D.H. 2002. Rats fed only during the light period are resistant to stress-induced weight loss. Physiol. Behav. 76:543-550.

Hazenberg J.G., Lee T.C. \& Taylor D. 2006. The role of osteocytes in functional bone adaptation. Bonekey Osteovision 3:10-16.

Iwaniec U.T. \& Turner R.T. 2008. Animal models for osteoporosis, p.9851009. In: Marcus R., Feldman D., Nelson D. \& Rosen C.J. (Eds), Osteoporosis. Academic Press, San Diego.

Jee W.S.S. \& Yao W. 2001. Overview: Animal models of osteopenia and osteoporosis. J. Musculoskel. Neuron. Interact. 1:193-207.

Lafage-Proust M.H., Boudignon B. \& Thomas T. 2003. Glucocorticoid-induced osteoporosis: Pathophysiology data and recent treatments. Joint Bone Spine 70:109-118.

Leslie W.D., Metge C., Salamon E.A. \& Yuen C.K. 2002. Bone mineral density testing in healthy postmenopausal women. J. Clin. Densitom. 5:117-130.

Levine S. 2005. Developmental determinants of sensitivity and resistance to stress. Psychoneuroendocrinology 30:939-946.

Lucca G., Comim C.M., Valvassori S.S., Réus G.Z., Vuolo F., Petronilho F., Dal-Pizzol F., Gavioli E.C. \& Quevedo J. 2009. Effects of chronic mild stress on the oxidative parameters in the rat brain. Neurochem. Int. 54:358-362.

Manelli F. \& Giustina A. 2000. Glucocorticoid-induced osteoporosis. Trends Endocrinol. Metabol. 11:79-85.

Marin M.T., Cruz F.C. \& Planeta C.S. 2007. Chronic restraint or variable stresses differently affect the behavior, corticosterone secretion and body weight in rats. Physiol. Behav. 90:29-35.

Mcllwain H.H. 2003. Glucocorticoid-induced osteoporosis: Pathogenesis, diagnosis, and managenment. Prev. Med. 36:243-249.

Mounach A., Abayi M., Ghazi M., Ghozlani I., Nouijai A., Achemlal L., Bezza A. \& El Maghraoui A. 2009. Discordance between hip and spine bone mineral density measurement using DXA: Prevalence and risk factors. Semin. Arthritis Rheum. 38:467-471.

Odén A., McCloskey E.V., Kanis J.A., Harvey N.C. \& Johansson H. 2015. Burden of high fracture probability worldwide: secular increase 20102040. Osteoporos. Int. 26:2243-2248.

Pacak K. \& McCarty R. 2000. Acute stress response: experimental, p.7-14. In: Fink G. (Ed.), Encyclopedia of Stress. Academic Press, San Diego.

Parfitt A.M., Drezner M.K., Glorieus F.H., Kanis J.A., Malluche H., Meunier P.J., Ott S.M. \& Recker R.R. 1987. Bone histomorphometry: Standardization of nomenclature, symbols, and units. J. Bone Miner. Res. 2:595-610.

Patschand D., Loddenkemper K. \& Buttgereit F. 2001. Molecular mechanisms of glucocorticoid-induced osteoporosis. Bone 29:498-505.
Retana-Márquez S., Bonilla-Jaime H., Vázquez-Palacios G., Martínez-García R. \& Velázquez-Moctezuma J. 2003. Changes in masculine sexual behavior, corticosterone and testosterone in response to acute and chronic stress in male rats. Horm. Behav. 44:327-337.

Riggs B.L., Khosla S. \& Melton L.J. 2002. Sex steroids and the construction and conservation of the adult skeleton. Endocr. Rev. 23:279-302.

Saarelainen J., Rikkonen T., Honkanen R., Kröger H. \& Tuppurainen M. 2007. Is discordance in bone measurementes affected by body composition or anthopometry?: a comparative study between peripheral and central devices. J. Clin. Densitom. 10:312-318.

Sambrook P. \& Lane N.E. 2001. Corticosteroid osteoporosis. Best Pract. Res. Clin. Rheumatol. 15:401-413.

Sengupta S., Ars: had M., Sharma S., Dubey M. \& Singh M.M. 2005. Attainment of peak bone mass and bone turnover rate in relation to estrous cycle, pregnancy and lactation in colony-bred Sprague-Dawley rats: Suitability for studies on pathophysiology of bone and therapeutic measures for its management. J. Steroid Biochem. Mol. Biol. 94:421-429.

Shea J.E. \& Miller S.C. 2005. Skeletal function and structure: Implications for tissue-target therapeutics. Adv. Drug Deliv. Rev. 57:945-957.

Stroud L.R., Salovey P. \& Epel E.S. 2002. Sex differences in stress responses: Social rejection versus achievement stress. Biol. Psychiatry 52:318-327.

Syed Z. \& Khan A. 2002. Bone densitometry: applications and limitations. J. Obstet. Gynaecol. Can. 24:476-485.

Tamura Y., Okinaga H. \& Takami H. 2004. Glucocorticoid-induced osteoporosis. Biomed. Pharmacother. 58:500-504.

Tsuchiya T. \& Horii I. 1995. Different effects of acute and chronic immobilization stress on plasma testosterone levels in male syrian hamsters. Psychoneuroendocrinology 20:95-102.

Turner R.T., Maran A., Lotinun S., Hefferan T., Evans G.L., Zhang M. \& Sibonga J.D. 2001. Animal models for osteoporosis. Rev. Endocr. Metab. Disord. 2:117-127.

Turner C.H. \& Burr D.B. 1993. Basic biomechanical measurements of bone: a tutorial. Bone 14:595-608.

Weinstein R.S. \& Manolagas S.C. 2000. Apoptosis and osteoporosis. Am. J. Med. 108:153-164.

Weinstein R.S., Wan C., Liu Q., Wang Y., Almeida M., O’Brien C.A., Thostenson J., Roberson P.K., Boskey A.L., Clemens T.L. \& Manolagas S.C. 2010. Endogenous glucocorticoids decrease skeletal angiogenesis, vascularity, hydration, and strength in aged mice. Aging Cell 9:147-161.

Willner P. 1997. Validity, reliability and utility of the chronic mild stress model of depression: a 10-year review and evaluation. Psychopharmacology 134:319-329.

World Health Organization 1994. Assessment of fracture risk and its application to screening for postmenopausal osteoporosis. WHO Technical Report Series 843.130p.

World Health Organization 2003. Prevention and management of osteoporosis. WHO Technical Report Series 921. 193p.

Yirmiya R., Goshen I., Bajayo A., Kreisel T., Feldman S., Tam J., Trembovier V., Csernus V., Shohami E. \& Bab I. 2006. Depression induces bone loss through stimulation of the sympathetic nervous system. PNAS 103:16876-16881.

Ziegler R. \& Kasperk C. 1998. Glucocorticoid-induced osteoporosis: Prevention and treatment. Steroids 63:344-348. 